\title{
The Effect of $\mathrm{N}$-acetyl Cysteine on Liver Function after On-pump Coronary Artery Bypass Graft Surgery: A Double-Blind Randomized Clinical Trial
}

fatemeh javaherforooshzadeh ( $\sim$ f_javaherforoosh@yahoo.com )

Ahvaz Jundishapur University of Medical Sciences: Ahvaz Jondishapour University of Medical Sciences pegah abbasi hormozi

Ahvaz Jundishapur University of Medical Sciences: Ahvaz Jondishapour University of Medical Sciences

Reza Akhondzadeh

Ahvaz Jundishapur University of Medical Sciences: Ahvaz Jondishapour University of Medical Sciences

Alireza olapour

Ahvaz Jundishapur University of Medical Sciences: Ahvaz Jondishapour University of Medical Sciences

Syed jalal Hashemi

Ahvaz Jundishapur University of Medical Sciences: Ahvaz Jondishapour University of Medical Sciences

\section{Research Article}

Keywords: N-acetyl cysteine, Liver function test, Cardio-Pulmonary Bypass, ALT, AST

Posted Date: August 4th, 2021

DOI: https://doi.org/10.21203/rs.3.rs-636977/v1

License: (c) (i) This work is licensed under a Creative Commons Attribution 4.0 International License.

Read Full License 


\section{Abstract}

Purpose: Somebody's organ dysfunctions such as heart, lung, kidney, and liver dysfunction are associated with the cardiopulmonary bypass in open-heart surgery.

This study aimed effect of the $\mathrm{N}$-acetyl cysteine injection on liver function after on-pump Coronary Artery Bypass Graft Surgery

Method: In this clinical trial conducted in Golestan Hospital, Ahvaz, Iran, 60 candidates for coronary artery bypass graft surgery were selected based on the inclusion criteria. The candidates were then randomly divided into two intervention and control groups (30 people each).Intervention: Patients received 3 (2 intraoperative and 1 postoperative) doses of IV N-acetyl cysteine $(100 \mathrm{mg} / \mathrm{kg})(\mathrm{n}=30)$ or placebo $(\mathrm{n}=30)$ over 24 hour. The main outcomes were serum Alkaline Phosphatase, Aspartate Aminotransferase, Alanine Aminotransferase, Bilirubin, PTT, and INR at 4 and 48 hours after surgery. Statistical analysis: The dates were analyzed using SPSS 22. Descriptive statistics were reported as mean \pm standard deviation for continuous variables and as frequency and percentage for categorical variables. An unpaired t-test was used to compare the parameters with a normal distribution. Statistical significance level was defined at $p$-value $<0.05$.

Results: there were significant differences in terms of, ALT, AST, ALP and Bilirubin levels 4(p-value < $0.001)$ and $48 \mathrm{~h}$ after surgery $(\mathrm{p}$-value $=0.002)$.

Conclusion: Based on the findings, intravenous administration of $\mathrm{N}$-acetyl cysteine in patients with CABG significantly may be preserved liver function.

Trial registry: Registered under No. Trial registration number IRCT20190506043492N2, date of registration :2020.05.23 .Retrospectively registered

\section{Introduction}

Open cardiac surgery requires the use of an artificial heart-lung device or cardiopulmonary bypass, which is responsible for the operation of the heart, lungs, and circulatory system during surgery. The cardiopulmonary bypass has important effects on body organs including the liver as the main organ for metabolism due to the stimulation of the coagulation system, immune system, complement system, hypothermia, and the presence of no pulsatile flow. In the liver, it disrupts oxygen transport, hepatic metabolism, and hepatic blood flow. However, it is suspected that various factors such as prolonged CPB time, massive transfusions, the type of surgery are the causes of liver injury $(1,2)$.

In cardiac surgery, about $10 \%$ of patients receiving CPB experience liver damage that directly affects the disease and mortality. The two main pathophysiological mechanisms for liver damage after CPB include systemic inflammatory response syndrome (SIRS) and oxidative stress (3). 
Changes in hepatic blood flow are an important factor in the pathogenesis of postoperative hepatic impairment. Increased serum concentrations of ALT and AST indicate a decrease in hepatocytes as their activity in serum is one of the most important indicators for assessing liver damage (4).

Glutathione is one of the most important antioxidants that can protect the body against oxidative stress (5). Increasing intracellular statin using glutathione and its precursors, such as $\mathrm{N}$-acetyl cysteine (NAC), can stimulate GSH synthesis, increase glutathione S-transferase (GST) activity, increase detoxification, and induce direct reaction with oxidizing radicals. $(6,7)$ Treatment with $\mathrm{N}$-acetyl cysteine supplementation appears to increase glutathione, the body's main antioxidant. $(8,9)$

Cardiac surgery with cardiopulmonary bypass (CPB) can be increased the risk of mesenteric ischemia and liver injury(10). Numerous approaches have been used for organ protection; however, some disagreements exist. Serum levels of Aspartate aminotransferase i.e. AST (SGOT) and Alanine aminotransferase i.e. ALT (SGPT) are very sensitive and predictive biomarkers of liver injury.(11)

The effects of NAC on organ protection in several organs have been investigated. (11). However, evaluation of the effects of NAC on liver function in patients undergoing open-heart surgery is inadequate. Therefore, this randomized clinical trial was designed to investigate the effect of NAC on liver function after CABG.

- Aim:

This study aimed to observe the effect of N-acetyl cysteine injection on liver function after on-pump Coronary Artery Bypass Graft Surgery

\section{Material And Method}

\section{Study design and Ethical statement}

This double-blind randomized clinical trial was conducted in Golestan Hospital, Ahvaz, Iran, from April 2020- January 2021 with ethics code No. IR.AJUMS.REC.1398.391 was received from Anesthesiology and Pain Research Center, Ahvaz Jundishapur University of Medical Sciences, Ahvaz, Iran. The trial was registered under No. IRCT20190506043492N2. Sixty patients undergoing elective on-pump coronary artery bypass graft surgery were included in the study. The objectives and potential risks and benefits of the study were clearly explained and written consent was obtained from all subjects.

\section{Setting and patients:}

- inclusion criteria:

On-pump CABG, age 30 to 70 years, normal liver function and normal renal function

\section{- Exclusion criteria:}


Emergent or urgent surgery, Patient refusal, Uncontrolled diabetes mellitus, steroids users, EF $<35 \%$, thyroid dysfunction, allergy to $\mathrm{N}$-acetyl cysteine

Randomization and Blindness: The patients were randomized using the simple incidental method, after recognizing appropriate individuals, they were randomly distributed a three-digit exclusive code using the random table. The final digit on the right concludes the patient group. If the figure is $0,1,2,3,4$ it was located in the intervention group (NAC), and if the figure is $5,6,7,8,9$ it was situated in the control group (normal saline as control). To ensure that, the patients the surgeon, and the investigators were blind to the treatment group before the study begins, we used a computer-generated allocation-concealment process before recruiting the patients. The patients, surgeon, and investigator were unaware of the type of injectable drug and the surgeries performed by the same surgeon (The injectable drug was prepared by the researcher and named 1 and 2).

\section{- Sample size:}

The sample size was calculated using the sample size estimation formula. The confidence interval $(\mathrm{Cl})$ level was considered to be $95 \%$. power $=0.8 ; \beta=0.2 ; \alpha=0.02$, using sample size software (PASS 2005, NCSS LLC, Kaysville, Utah, USA) and using this equation: (12):

$2[(Z \beta+Z a) \sigma / \Delta] 2$

$Z a=1.96$

$\cdot Z \beta=0.84$

$\cdot \sigma($ estimated sd based on similar studies $)=5$

- $\Delta=$ the estimated effect size $=3$

The final sample size in each group was 45 which was increased to 50 in each group

During the study period, 100 patients undergoing CABG surgery met the eligibility criteria to participate in the trial. 30 patients did not meet the inclusion criteria. 10 patients had emergent or urgent surgery. Eventually, 60 patients were enrolled in the study. They were assigned into two groups of NAC and control, 30 patients each. Consort diagram (Figure1). Eventually, 60 patients were included in the study. The subjects were assigned to two groups of intervention and control, 30 patients each.

\section{- Anesthesia protocol:}

In the operating room, standard monitoring included five-lead electrocardiography, and pulse oximetry was inserted. An arterial line for continuous blood pressure monitoring and blood gases management was introduced. The anesthesia technique, the surgeon, and the cardiopulmonary bypass procedure was intended to be as similar as possible. The patients after surgery were admitted to the cardiovascular ICU. Protocol for sedation (Dexmedetomidine 0/1-0.5 $\mu \mathrm{g} / \mathrm{kg} / \mathrm{min}$ ), and management of mechanical 
ventilation (SIMV mode of ventilation) were similar for all patients and if they matched the weaning criteria, were extubated.

\section{- Intervention:}

In the intervention group, after induction of anesthesia and intubation, and hemodynamic stabilization, $100 \mathrm{mg} / \mathrm{kg} \mathrm{N}$-acetyl cysteine that diluted in $100 \mathrm{ccs}$ normal saline will be administered intravenously in $20 \mathrm{~min}, 100 \mathrm{mg} / \mathrm{kg}$ in the Next 4 hours and $100 \mathrm{mg} / \mathrm{kg}$ in the 16 hours after on. In the control group, normal saline will be administered in the same volume and at the same time.

Primary outcomes were serum Alkaline Phosphatase, Aspartate Aminotransferase, Alanine Aminotransferase, Bilirubin, PTT, and INR at 4 and 48 hours after surgery. Secondary outcomes included the hemodynamic variables, Blood products Transfusion.

\section{Statistical analysis:}

Numerical variables were reported as mean \pm standard deviation (SD). Parameters with a normal distribution were compared using the unpaired t-test and repeated measurement. P-value $\leq 0.05$ was considered to be a statistical significance level. All analyses were done using SPSS 22.0 (SPSS Inc, Chicago, IL, USA).

\section{Results}

During the study period, 100 patients undergoing CABG surgery met the eligibility criteria to participate in the trial. 30 patients did not meet the inclusion criteria. 10 patients had emergent or urgent surgery. Eventually, 60 patients were enrolled in the study. They were assigned into two groups of NAC and control, 30 patients each.

There were no significant differences between the two groups in terms of demographic characteristics including age, sex ratio, weight, EF, history of diabetes, smoking, HTN and HLP, Duration of surgery, CPB time, Cross clump time. $(P>0.05)$ (Table 1$)$ 
Table 1

Demographic data of patients in the intervention and control groups

\begin{tabular}{|c|c|c|c|c|}
\hline \multicolumn{2}{|c|}{ Parameter } & \multirow{2}{*}{$\begin{array}{l}\text { NAC } \\
22(73.4)\end{array}$} & \multirow{2}{*}{\begin{tabular}{|l} 
Control \\
$24(80)$
\end{tabular}} & \multirow{2}{*}{$\begin{array}{l}\text { P-Value } \\
0.761\end{array}$} \\
\hline Sex & Male $\mathrm{n}(\%)$ & & & \\
\hline & Female n(\%) & $8(26.6)$ & $6(20)$ & \\
\hline \multicolumn{2}{|c|}{ Age(Year) } & $65.43 \pm 14.850$ & $63.00 \pm 10.932$ & 0.178 \\
\hline \multicolumn{2}{|c|}{ Weight(Kg) } & $82.23 \pm 14.231$ & $79.80 \pm 12.452$ & 0.785 \\
\hline \multicolumn{2}{|c|}{ LVEF(\%) } & $45.67 \pm 5.371$ & $48.83 \pm 4.086$ & 0.181 \\
\hline \multicolumn{2}{|c|}{ Diabetes n(\%) } & $27(90)$ & $23(76.6)$ & 0.381 \\
\hline \multicolumn{2}{|c|}{ Smoking $\mathbf{n}(\%)$} & 25(83.3) & $20(66.6)$ & 0.326 \\
\hline \multicolumn{2}{|c|}{ HTN n(\%) } & $24(80)$ & $27(90)$ & 0.236 \\
\hline \multicolumn{2}{|c|}{ HLP n(\%) } & $23(76.6)$ & $24(80)$ & 0.501 \\
\hline \multicolumn{2}{|c|}{ Duration of surgery (min) } & $204.67 \pm 41.646$ & $211.00 \pm 34.476$ & 0.524 \\
\hline \multicolumn{2}{|c|}{ CPB time(min) } & $44.33 \pm 11.198$ & $44.67 \pm 9.679$ & 0.391 \\
\hline \multicolumn{2}{|c|}{ ACC time(min) } & $59.00 \pm 14.468$ & $64.83 \pm 25.680$ & 0.213 \\
\hline
\end{tabular}

There were significant differences in ALP $(P<0.001)$, AST $(P=0.02)$, ALT $(P<0.001)$, Bilirubin $(P=0.01)$, $\operatorname{PTT}(P<0.001)$, and INR $(P=0.005)$ levels between the two groups at 4 hours after surgery. There were significant differences in ALP $(P=0.002)$, AST $(P<0.001)$, ALT $(P=0.001)$, and Bilirubin $(P=0.004)$ levels between the two groups at 48 hours after surgery. These levels were significantly lower in the NAC group. PTT and INR were not significant at $48 \mathrm{~h}$ after surgery between groups. (Table 2 ) 
Table 2

Effect of administration of $\mathrm{N}$-acetylcysteine on liver enzyme test in two groups

\begin{tabular}{|c|c|c|c|c|}
\hline \multicolumn{2}{|c|}{ Parameters } & \multirow{2}{*}{$\begin{array}{l}\text { NAC Group } N=30 \\
128.07 \pm 45.540\end{array}$} & \multirow{2}{*}{$\begin{array}{l}\text { Control Group N = } 30 \\
203.00 \pm 77.635\end{array}$} & \multirow{2}{*}{$\begin{array}{l}\text { P-Value } \\
0.112\end{array}$} \\
\hline ALP & Baseline & & & \\
\hline & After CPB time & $119.80 \pm 41.741$ & $184.60 \pm 64.078$ & $<0.001$ * \\
\hline & 48h after surgery & $113.70 \pm 43.760$ & $155.57 \pm 56.125$ & 0.002 * \\
\hline & P-Value & $<0.05$ & $<0.05$ & \\
\hline \multirow[t]{4}{*}{ AST } & Baseline & $40.77 \pm 18.379$ & $46.27 \pm 12.031$ & 0.176 \\
\hline & After CPB time & $35.30 \pm 15.369$ & $43.20 \pm 11.226$ & 0.02 * \\
\hline & $48 \mathrm{~h}$ after surgery & $28.80 \pm 10.924$ & $40.37 \pm 10.746$ & $<0.001$ * \\
\hline & P-Value & $<0.05$ & $<0.05$ & \\
\hline \multirow[t]{4}{*}{ ALT } & Baseline & $40.37 \pm 10.746$ & $41.33 \pm 14.452$ & 0.297 \\
\hline & After CPB time & $36.77 \pm 13.398$ & $37.17 \pm 16.197$ & $<0.001$ * \\
\hline & $48 \mathrm{~h}$ after surgery & $28.80 \pm 10.924$ & $34.63 \pm 15.655$ & 0.001 * \\
\hline & P-Value & $<0.05$ & $<0.05$ & \\
\hline \multirow[t]{4}{*}{ Bilirubin } & Baseline & $0.72 \pm 0.218$ & $1.63 \pm 6.493$ & 0.324 \\
\hline & After CPB time & $0.55 \pm 0.211$ & $0.66 \pm 0.257$ & 0.01 * \\
\hline & $48 \mathrm{~h}$ after surgery & $0.45 \pm 0.140$ & $0.50 \pm 0.202$ & 0.004 * \\
\hline & P-Value & $<0.05$ & $<0.05$ & \\
\hline \multirow[t]{4}{*}{ PTT } & Baseline & $32.80 \pm 0.42$ & $32.90 \pm 1.13$ & 0.81 \\
\hline & After CPB time & $38.77 \pm 3.67$ & $41.83 \pm 0.56$ & $<0.001^{\star}$ \\
\hline & $48 \mathrm{~h}$ after surgery & $32.43 \pm 0.85$ & $30.00 \pm 1.37$ & 0.07 \\
\hline & P-Value & $<0.05$ & $<0.05$ & \\
\hline \multirow[t]{3}{*}{ INR } & Baseline & $1.09 \pm 0.12$ & $1.07 \pm 0.01$ & 0.78 \\
\hline & After CPB time & $1.35 \pm 0.01$ & $1.43 \pm 0.04$ & $0.005^{\star}$ \\
\hline & $48 \mathrm{~h}$ after surgery & $1.12 \pm 0.09$ & $1.19 \pm 0.02$ & 0.09 \\
\hline
\end{tabular}

ALP: Alkaline Phosphatase; AST: Aspartate Aminotransferase; ALT: Alanine aminotransferase PTT: Partial thromboplastin time; INR: International normalized ratio

Data are expressed as mean \pm SD. The statistical test used was the t-test and repeated measurement. $\mathrm{P}<0.05$; t-test analysis and repeated measurement demonstrated difference between the groups with 
Parameters

NAC Group N = $30 \quad$ Control Group N = 30

P-Value

P-Value

0.476

0.345

ALP: Alkaline Phosphatase; AST: Aspartate Aminotransferase; ALT: Alanine aminotransferase PTT: Partial thromboplastin time; INR: International normalized ratio

Data are expressed as mean \pm SD. The statistical test used was the t-test and repeated measurement. $P<0.05$; t-test analysis and repeated measurement demonstrated difference between the groups with

Significant differences were observed between the two groups in terms of MAP levels during CPB time ( $P$ $=0.002)$ and within $48 \mathrm{~h}$ after surgery $(p<0 / 001)$. However, there was no significant difference between the two groups in terms of HR in any time $(p>0 / 05)$. (Table 3$)$

Table 3

Effect of administration of NAC on hemodynamic variables

\begin{tabular}{|c|c|c|c|c|}
\hline \multicolumn{2}{|c|}{ Parameters } & \multirow{2}{*}{$\begin{array}{l}\text { NAC Group N = } 30 \\
78.20 \pm 9.163\end{array}$} & \multirow{2}{*}{$\begin{array}{l}\text { Control Group N = } \mathbf{3 0} \\
80.93 \pm 11.608\end{array}$} & \multirow{2}{*}{$\begin{array}{l}\text { P-Value } \\
0.685\end{array}$} \\
\hline HR & Baseline & & & \\
\hline & After CPB time & $76.07 \pm 11.712$ & $78.53 \pm 10.391$ & 0.872 \\
\hline & Within 48 hours after surgery & $75.67 \pm 13.583$ & $76.50 \pm 8.842$ & 0.896 \\
\hline & P-Value & 0.456 & 0.567 & \\
\hline \multirow[t]{4}{*}{ MAP } & Baseline & $119.77 \pm 19.163$ & $133.77 \pm 24.241$ & 0.324 \\
\hline & During CPB time & $92.87 \pm 12.190$ & $98.10 \pm 22.550$ & 0.002 * \\
\hline & Within 48 hours after surgery & $82.20 \pm 14.346$ & $85.80 \pm 13.499$ & $<0.001$ * \\
\hline & P-Value & 0.001 & 0.001 & \\
\hline \multicolumn{5}{|c|}{ NAC: N-acetyl cysteine ;HR: Heart rate ;MAP: Mean arterial pressure. } \\
\hline $\begin{array}{l}\text { Daté } \\
\mathrm{P}<\mathrm{C} \\
\star\end{array}$ & $\begin{array}{l}\text { xpressed as mean } \pm S D \text {. Th } \\
\text { test analysis and repeated }\end{array}$ & $\begin{array}{l}\text { tical test used } v \\
\text { rement demonst }\end{array}$ & $\begin{array}{l}\text { e t-test and repeated } n \\
\text { difference between th }\end{array}$ & $\begin{array}{l}\text { surement } \\
\text { roups with }\end{array}$ \\
\hline
\end{tabular}

Comparison of the two groups about blood transfusion products showed that; there was a significant difference between the two groups in terms of Packed. Cell $(P=0.002)$, and FFP $(P<0.001)$, transfusion . (Table 4) 
Table 4

Comparison of blood products transfusion between the two groups

\begin{tabular}{|llll|}
\hline Parameters & NAC Group $\mathbf{N}=\mathbf{3 0}$ & Control Group $\mathbf{N}=\mathbf{3 0}$ & P-Value \\
\hline P.C & $2.10 \pm 1.094$ & $2.80 \pm 1.126$ & 0.002 * \\
\hline FFP & $1.02 \pm 1.548$ & $1.63 \pm 1.377$ & $<0.001$ * \\
\hline NAC: N-acetyl cysteine; P.C: Packed cell; FFP: Fresh Frozen Plasma & \\
\hline $\begin{array}{l}\text { Data are expressed as mean } \pm \text { SD. The statistical test used was the t-test. } \mathrm{P}<0.05 ; \text { t-test analysis } \\
\text { demonstrated difference between the groups with* }\end{array}$ & \\
\hline
\end{tabular}

\section{Discussion}

The main purpose of this study was to evaluate the effect of $\mathrm{N}$-acetyl cysteine on liver function in patients undergoing elective coronary artery bypass surgery.

The results of our study showed that administration of $\mathrm{N}$-acetyl cysteine in patients undergoing CABG had a further decrease in the levels of ALP, AST, ALT, bilirubin, PTT, and INR after surgery, that indicating the positive effect of the drug on liver function.

Some previous studies have shown that the antioxidant and anti-inflammatory role of $\mathrm{N}$-acetyl cysteine is very effective in protecting the body's organs in many important systems, including the liver, which is consistent with our findings (13).

In a comprehensive study by Singh et al., intravenous injection of $\mathrm{N}$-acetyl cysteine in all types of acute liver failure was able to significantly improve hepatic serological biomarkers (13). This study confirmed the hepatic outcomes in our research.

Didem Onk, et al., showed that the pretreatment by N-acetylcysteine can improve hepatic functions by regulation of the metabolism of the ammonia and nitrogen, and reduction of lactate in patients with chronic obstructive pulmonary disease who undergo coronary artery bypass grafting surgery(14).

Sayed et al. examined the effect of $\mathrm{N}$-acetyl cysteine use on liver enzymes in patients undergoing liver surgery. The results showed that ALT and AST levels were significantly lower after surgery in the N-acetyl cysteine receiving intervention group than in the control group. They concluded that injection of $\mathrm{N}$-acetyl cysteine in patients undergoing liver surgery could reduce enzyme levels and subsequent liver damage (15). The results of this study are in line with the present research.

Shafiei et al. study showed that there was a significant reduction in troponin-I and lactate level in the treatment groups ( $\mathrm{N}$-acetyl cysteine and melatonin) compared to the placebo arm indicating that $\mathrm{N}$-acetyl cysteine and melatonin were able to prevent the post-CABG cardiac injury(16). 
Beyaz et al. studied 41 patients who were candidates for laparoscopic surgery to evaluate the effect of Nacetyl cysteine use on liver function following general anesthesia. The decrease in AST, ALT, LDH, and GGT levels was lower in 1 and 24 hours after surgery than in the control group. They concluded that liver function was better maintained by using $\mathrm{N}$-acetyl cysteine during general anesthesia (17).

Yazdi et al. studied the effect of $\mathrm{N}$-acetyl cysteine on liver function in patients undergoing isoflurane anesthesia to investigate its effects on the hepatic complications of this type of anesthesia. They concluded that $\mathrm{N}$-acetyl cysteine could significantly reduce liver enzymes compared to the control group after administration of isoflurane (18). Both of the above studies are consistent with the results of our study.

As mentioned earlier, the positive effects of this drug on liver protection are mainly attributed to its role as a precursor of glutathione and consequently its antioxidant effects (19). Also, $\mathrm{N}$-acetyl cysteine has been shown to maintain the activity of catalase, mitochondrial super oxidase dismutase, and various forms of glutathione peroxidase and keep membrane fluidity. These have been suggested as mechanisms involved in the preservation of the liver during biliary obstruction in rats (20).

In the study of Jin et al. the protective effect of $\mathrm{N}$-acetyl cysteine against liver damage was confirmed as it was able to inhibit the expression of TNF-a following ischemic liver damage and thereby reduce the extent of liver damage (20). Their results are consistent with the present study.

In a study by Ibrahim and Sharawy, the effect of intravenous infusion of $\mathrm{N}$-acetyl cysteine in cirrhotic patients undergoing abdominal surgery was investigated. Finally, it was shown that this intervention has led to the maintenance of liver and kidney function in these patients (21).

In a study by Fusai et al. in rabbits, animals with hepatic steatosis were treated with $\mathrm{N}$-acetyl cysteine. Similar to what was observed in our study, it was shown that this drug can reduce the level of ALT and, at the same time, significantly reduce liver cell damage (22).

In the study of Montero et al. in rats, the effect of N-acetyl cysteine administration on liver tissue after camp triad port was investigated. Compared with placebo, $\mathrm{N}$-acetyl cysteine significantly reduced serum levels of AST and ALT (23). The findings of these two studies are consistent with the results of the present study in terms of the positive effect of $\mathrm{N}$-acetyl cysteine on the reduction of liver enzymes related to liver function.

Several studies have been conducted to evaluate the protective effects of $\mathrm{N}$-acetyl cysteine on vital tissues and organs in patients undergoing heart surgery.

The results of a study by Sucu et al. showed that intravenous administration of $\mathrm{N}$-acetyl cysteine reduced the pump-induced inflammatory response during cardiopulmonary bypass(24).

In a study by Fathi et al., the effect of $\mathrm{N}$-acetyl cysteine on liver function in patients undergoing coronary artery bypass graft surgery was investigated. The results of this study showed a decrease in liver 
enzymes in patients receiving $\mathrm{N}$-acetyl cysteine compared to the control group. They recommended that all patients undergoing CABG receive $150 \mathrm{mg} / \mathrm{kg}$ of $\mathrm{N}$-acetyl cysteine in the form of prophylaxis(25).

Ristikankare et al. examined high doses of NAC to observe the protective role of $\mathrm{N}$-acetyl cysteine during cardiac surgery with CPB. Consistent with our results, the results of their study showed the beneficial effects of N-acetyl cysteine on the liver(26).

Contrary to the results of our study, Snowden and Prentis showed that the use of N-acetyl cysteine did not reduce alanine aminotransferase levels, meaning that it did not affect improving cell liver damage (27). On the other hand, in a study by Kemp et al., no significant improvement in postoperative outcomes of liver resection and hepatectomy was reported in patients receiving $\mathrm{N}$-acetyl cysteine, and the drug was considered ineffective(28).

Grendar et al. evaluated the effect of N-acetyl cysteine on liver recovery after resection and hepatectomy. They found $\mathrm{N}$-acetyl cysteine to be ineffective in the improvement of liver function(29).

Differences in the administration method and dosage of $\mathrm{N}$-acetyl cysteine may be involved in justifying this difference. Also, differences in sample size, type of surgery, and follow-up time are other reasons for this discrepancy in the results. The present study showed improvement in liver function and liver enzyme levels in patients undergoing coronary artery bypass graft surgery. The levels of ALP, AST, and ALT enzymes were further reduced in the group receiving $\mathrm{N}$-acetyl cysteine, which is of significant importance, especially in patients at risk of decreased visceral perfusion during surgery (especially during CPB) to reduce the risk of ischemia and liver damage. The results of our study showed that $\mathrm{N}$-acetyl cysteine significantly improved Liver Function Test (LFT) and could be effective in reducing ischemic liver damage. This effect of $\mathrm{N}$-acetyl cysteine can be due to its effects on the glutathione system (protective mechanism of the liver) or its anti-inflammatory and antioxidant effects.

\section{Limitations}

This study has several limitations. First, the sample size was small. Second, the study was single-center. We recommended further trials with large sample size, multi-center, and long follow-up duration.

\section{Conclusion}

In conclusion, intravenous administration of $\mathrm{N}$-acetyl cysteine in patients with CABG significantly may be preserved liver function.

\section{Declarations}

Conflicting Interest: There is no conflict of interest to be declared. 
Funding: Financial support for this study was provided by Ahvaz Jundishapur University of Medical Sciences.

Ethics approval: This paper was part of a thesis Ethics code: (IR.AJUMS. REC.1398.391 was received from Anesthesiology and Pain Research Center, Ahvaz Jundishapur University of Medical Sciences, Ahvaz, Iran. The RCT code of this study was IRCT20190506043492N2.

Consent to participate: Written informed consent signed by all of the patients.

Consent for publication: Authors provide formal written consent to publish before publication

Availability of data and material: All data were retrieved from the institutional database and are available from the corresponding authors upon reasonable request.

\section{Acknowledgment}

This paper was a part of a thesis with the Ethics code IR.AJUMS.REC.1398.391This study was designed as a placebo-controlled double-blind clinical trial (IRCT20190506043492N2). We sincerely thank the patients who cooperated with us in this project and supported the research team.

Authors' Contribution: F.JZ contributed in concept, study design, the definition of intellectual content; P. Ah collected data; F.JZ drafted the manuscript. A. O; provided study materials and patients' information. R. A and J.H; conceived of the study and participated in its design. All authors read and approved the final manuscript.

\section{References}

1. Zakeri S, Vafaey H, Banihashem N, Alijanpour A, Gholinia H, Behzad C. Evaluation of Liver Function Tests after Coronary artery bypass surgery (CABG). Caspian Journal of Internal Medicine. 2021;12(1):45-52.

2. Araujo L, Dombrovskiy V, Kamran W, Lemaire A, Chiricolo A, Lee LY, et al. The effect of preoperative liver dysfunction on cardiac surgery outcomes. Journal of cardiothoracic surgery. 2017;12(1):1-7.

3. Sabzi F, Faraji R. Liver function tests following open cardiac surgery. Journal of cardiovascular and thoracic research. 2015;7(2):49.

4. Javanamani R, Nakhostin-Roohi B. The Effect of One-week Glutamine Supplementation on Oxidative Stress Indices in Healthy Young Men. Journal of Ardabil University of Medical Sciences. 2015;15(1):83-9.

5. Lin Z, Cai F, Lin N, Ye J, Zheng Q, Ding G. Effects of glutamine on oxidative stress and nuclear factor-кB expression in the livers of rats with nonalcoholic fatty liver disease. Experimental and therapeutic medicine. 2014;7(2):365-70.

6. Gouvêa Junior VT, Caporossi C, Salomão AB, Côrtes E, Munhoz MF, Nascimento JEAd. Effect of glutamine on the total antioxidant system of rats subjected to renal ischemia and reperfusion. Acta 
cirurgica brasileira. 2011;26(6):445-50.

7. Zhang Y, Yan H, Lv S-G, Wang L, Liang G-P, Wan Q-X, et al. Effects of glycyl-glutamine dipeptide supplementation on myocardial damage and cardiac function in rats after severe burn injury. International journal of clinical and experimental pathology. 2013;6(5):821.

8. Sekhar RV, Liu CW, Rice S. Increasing glutathione concentrations with cysteine and glycine supplementation lowers inflammation in HIV patients. Aids. 2015;29(14):1899-900.

9. Bartekova M, Barancik M, Ferenczyova K, Dhalla NS. Beneficial effects of N-acetylcysteine and Nmercaptopropionylglycine on ischemia reperfusion injury in the heart. Current medicinal chemistry. 2018;25(3):355-66.

10. D’Oria R, Schipani R, Leonardini A, Natalicchio A, Perrini S, Cignarelli A, et al. The role of oxidative stress in cardiac disease: from physiological response to injury factor. Oxidative medicine and cellular longevity. 2020;2020.

11. Salameh A, Dhein S. Strategies for Pharmacological Organoprotection during Extracorporeal Circulation Targeting Ischemia-Reperfusion Injury. Front Pharmacol. 2015;6:296-.

12. Kadam P, Bhalerao S. Sample size calculation. Int J Ayurveda Res. 2010;1(1):55-7.

13. Singh S, Hynan LS, Lee WM, Group ALFS. Improvements in hepatic serological biomarkers are associated with clinical benefit of intravenous $\mathrm{N}$-acetylcysteine in early stage non-acetaminophen acute liver failure. Digestive diseases and sciences. 2013;58(5):1397-402.

14. Onk D, Özçelik F, Onk OA, Günay M, Ayazp lu TA, Ünver E. Assessment of Renal and Hepatic TissueProtective Effects of N-Acetylcysteine via Ammonia Metabolism: A Prospective Randomized Study. Medical Science Monitor : International Medical Journal of Experimental and Clinical Research. 2018;24:1540 - 6 .

15. Sayed E, Gaballah K, Younis E, Yassen K, El-Einen AK. The effect of intravenous infusion of N-acetyl cysteine in cirrhotic patients undergoing liver resection: A randomized controlled trial. Journal of anaesthesiology, clinical pharmacology. 2017;33(4):450.

16. Shafiei E, Bahtoei M, Raj P, Ostovar A, Iranpour D, Akbarzadeh S, et al. Effects of N-acetyl cysteine and melatonin on early reperfusion injury in patients undergoing coronary artery bypass grafting: $A$ randomized, open-labeled, placebo-controlled trial. Medicine (Baltimore). 2018;97(30):e11383-e.

17. Beyaz SG, Yelken B, Kanbak G. The effects of N-acetylcysteine on hepatic function during isoflurane anaesthesia for laparoscopic surgery patients. Indian journal of anaesthesia. 2011;55(6):567.

18. Yazdi B, Fard AJ, Akhtaran S, Khalili M, Mahmoodiyeh B. Effect of N-acetyl cysteine on Liver Function in General Anesthesia with Isoflurane. Biosciences Biotechnology Research Asia. 2016;13(3):151521.

19. Yang Y-Y, Lee K-C, Huang Y-T, Wang Y-W, Hou M-C, Lee F-Y, et al. Effects of N-acetylcysteine administration in hepatic microcirculation of rats with biliary cirrhosis. Journal of hepatology. 2008;49(1):25-33.

20. Jin X, Wang L, Wu H-S, Zhang L, Wang C-Y, Tian Y, et al. N-acetylcysteine inhibits activation of toll-like receptor 2 and 4 gene expression in the liver and lung after partial hepatic ischemia-reperfusion 
injury in mice. Hepatobiliary Pancreat Dis Int. 2007;6(3):284-9.

21. Ibrahim ES, Sharawy A. Effectiveness of intravenous infusion of $\mathrm{N}$-acetylcysteine in cirrhotic patients undergoing major abdominal surgeries. Saudi journal of anaesthesia. 2015;9(3):272.

22. Fusai G, Glantzounis GK, Hafez T, Yang W, Quaglia A, Sheth H, et al. N-acetylcysteine ameliorates the late phase of liver ischaemia/reperfusion injury in the rabbit with hepatic steatosis. Clinical science. 2005;109(5):465-73.

23. Montero E, Quireze Jr C, d'Oliveira D, editors. Bile duct exclusion from selective vascular inflow occlusion in rat liver: role of ischemic preconditioning and $\mathrm{N}$-acetylcysteine on hepatic reperfusion injury. Transplantation proceedings; 2005: Elsevier.

24. Sucu N, Cinel I, Unlu A, Aytacoglu B, Tamer L, Kocak Z, et al. N-acetylcysteine for preventing pumpinduced oxidoinflammatory response during cardiopulmonary bypass. Surgery today. 2004;34(3):237-42.

25. Fathi M, Baniani M, Forouzeshfard M, Rajaei S, Ghods K, Dabbagh A. Assessment the effect of N acetyl cysteine on liver function test in patient with elective coronary artery bypass grafting with cardiopulmonary bypass. Journal of Cellular \& Molecular Anesthesia. 2016;1(3):103-8.

26. Ristikankare A, Kuitunen T, Kuitunen A, Uotila L, Vento A, Suojaranta-Ylinen R, et al. Lack of renoprotective effect of iv $\mathrm{N}$-acetylcysteine in patients with chronic renal failure undergoing cardiac surgery. BJA: British Journal of Anaesthesia. 2006;97(5):611-6.

27. Snowden CP, Cressey DM. Anesthesia for hepatobiliary surgery. Gastrointestinal and colorectal anesthesia. 2006:213.

28. Kemp R, Mole J, Gomez D, Group NHS. Current evidence for the use of N-acetylcysteine following liver resection. ANZ journal of surgery. 2018;88(6):E486-E90.

29. Grendar J, Ouellet JF, McKay A, Sutherland FR, Bathe OF, Ball CG, et al. Effect of N-acetylcysteine on liver recovery after resection: A randomized clinical trial. Journal of surgical oncology. 2016;114(4):446-50.

\section{Figures}




\section{CONSORT 2010 Flow Diagram}

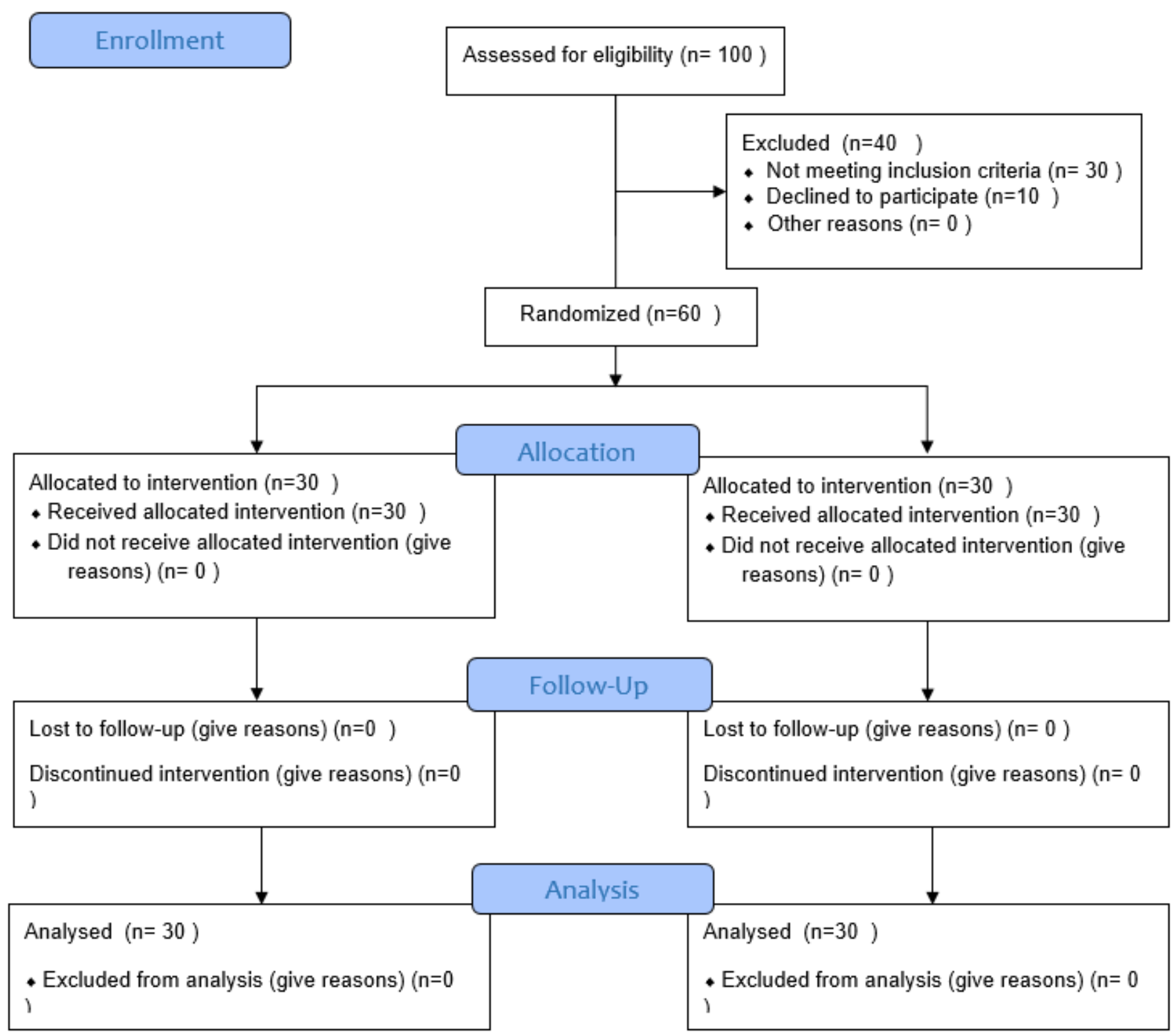

\section{Figure 1}

One hundred subjects were registered in the study, of which 60 met the criteria for the study and consented to participate. Patients were divided into two groups (each with 30 subjects). 